\title{
Overcoming the Copenhagen Failure with Flexible Commitments
}

\author{
JOSEPH STIGLITZ
}

\begin{abstract}
The fundamental issues presented by climate change are first, that the global environment is a global public good and second, the question of how to share the burden of providing a better climate. Everyone would like to "free ride" on the efforts of others, but there is disagreement over who is free riding. The Kyoto approach, based on dividing up emission rights, has an inberent problem in that such rights could easily reach a monetary value of over a trillion dollars a year. The approach suggested here avoids any attempt at a grand solution to the fair allocation of these rights. A low-carbon economy could be achieved through the imposition of a moderate carbon price, which would raise substantial revenue and allow a reduction in other taxes, thereby keeping the deadweight loss small. Countries should be given flexibility in how they meet their obligations-whether through a carbon tax, a system of cap and trade, or even possibly certain regulatory mechanisms. But a fully voluntary agreement likely cannot include countries that export a significant amount of fossil fuel. A green fund financed by allocating say 20\% of carbon revenues collected in developed countries could be used to implement "differentiated responsibilities."
\end{abstract}

Keywords: Climate change, Global warming, Carbon pricing, UN climate negotiations

http://dx.doi.org/10.5547/2160-5890.4.2.jsti

\section{* INTRODUCTION}

There is by now widespread agreement that climate change represents an existential threat, that only by global action can the accumulation of greenhouse gases in the atmosphere be stymied, and that there has to be some appropriate form of burden sharing (see, in particular, Stiglitz, 2011). There is even broad consensus over the urgency of action; that unless we act soon, there is a serious likelihood of an increase in temperature well above the 2 degrees $\mathrm{C}$ that was at the core of the Copenhagen agreement. Yet, in spite of the broad consensus, there has been little progress. There has been some-but the voluntary measures taken by various countries simply don't add up to what is needed. This paper (like others in this symposium) attempts to explain why that may be the case and point to an alternative framework for negotiations which, I believe, is more promising than that on which the world has embarked since the Rio agreement of 1992.

The fundamental issues are simple to state but hard to resolve: the global environment is a global public good-all benefit from a good environment, and all suffer from climate change (Stiglitz 1995, 2006a, 2006b, 2006c). As in the case of any public good, there is a problem of undersupply; everyone would like to "free ride" off the efforts of others in supplying the

\footnotetext{
${ }^{a}$ Columbia University, U.S.A.

Economics of Energy \& Environmental Policy, Vol. 4, No. 2. All rights reserved.
} 
public good. In the case of global warming (climate change) there is an additional problem: some suffer more from the consequences of climate change than others; the adjustments some have to make to avoid climate change are greater for some than others; and the ability of some to take the actions to reduce emissions and to adapt to the consequences are greater for some than others. Indeed, it used to be thought that the countries like the United States that were the largest contributors to climate change would be the ones that would suffer the least from it. As we have become more aware of the multiple effects of climate change (including on weather variability), that view is not held so strongly today: rich countries like the United States are vulnerable to more property damage from events like Hurricane Sandy. ${ }^{1}$ Moreover, poor countries are today responsible for an increasing share of carbon emissions.

Still, the central issue in reaching a global agreement entails burden sharing-who should pay the price associated with reducing greenhouse gas emissions? Should it be the large developed countries who have so far contributed most to the increase in greenhouse gases over the past two hundred years? Should poorer developing countries be asked to sacrifice their growth potential, so that the advanced countries can continue in their emissions-intensive life style?

Some suggest that it should be easy to arrive at an agreement. Whenever there are large externalities - and greenhouse gases give rise to a huge externality — there are arrangements that are Pareto superior; where all would be better off rather than carrying on in a "business as usual" manner. But the problem in this case is that these Pareto improvements would entail developing countries making significant sacrifices which they view they can ill afford, so that the developed countries can continue in their profligate patterns-or so that developed countries could be compensated for not continuing in their profligate patterns. This is because those in the developing world, disproportionately located in the tropics, are likely to be hurt most by climate change; though there is increasing evidence that some of the extreme weather events associated with climate change will affect even those living in more moderate climates, that many of these countries will be adversely affected by sea level changes, and that all could be affected by disease vectors.

Perhaps, in the end, when developing countries face the bleak alternative of desertification, droughts, flooding, etc. they will be willing to make the sacrifices, as unfair as they may seem. Perhaps, in the end, citizens in the more developed country will feel a stronger moral obligation to bear their fair share of the burden. This paper, however, is written in the hope that there is scope for arriving at a negotiated solution sooner rather than later.

\section{* THE FAILURE OF THE CURRENT APPROACH}

The Kyoto approach, based on allocating "emission rights" (which could be traded) to different countries, has an inherent problem. It is now widely recognized that emission rights have a monetary value-probably on the order of $\$ 80$ to $\$ 100$ a ton in an emissions control scheme achieving the 2 degree goal. Giving a country emission rights is equivalent to giving them money. A global agreement has to decide on how to allocate an asset worth some trillion dollars a year. No wonder that it is hard to reach an agreement.

1. "It is readily apparent that the storm surge and associated damage [from Sandy] was considerably influenced by climate change." From "Attribution of climate extreme events," K. Trenberth et al., Nature Climate Change, Perspective, 22 June 2015. www.nature.com/nclimate/journal/vaop/ncurrent/pdf/nclimate2657.pdf. 
Inevitably, if there is to be an agreement, the world will have to decide on some principles of allocation - a formula. The debate will focus on the terms of the allocation formula.

Kyoto seemed based on a principle that worked imperfectly among developed countries, but will simply not work when developing countries are brought in: countries were asked to make a given percentage reduction relative to their prior levels of emissions. Negotiations focused on adjustments up or down from the base rate, defended on grounds of particular circumstances facing particular countries. But this principle essentially says that those who emitted more in the past have the right to emit more in the future. No developing country would or should agree to this principle.

There are alternative principles that seem more ethically justifiable. One would divide the world's carbon "space" according to population in 1992, when the problem of global warming was globally recognized. Some countries, like the US, have essentially already used up all of their carbon space. Thus, they either need to move to zero net emissions or purchase emission permits from others.

There are of course more "progressive" allocations. Conventional principles would allocate a global asset such as emission rights in a progressive manner, with poorer countries getting a larger allocation. Many would argue that in allocating carbon space, one should go back in time well before 1992; and since the developed countries were responsible for the overwhelming proportion of the increase in carbon concentration over the past two hundred and fifty years, that would imply that they would have to reduce their carbon emissions going forward even more.

The approach suggested here implies avoiding any attempt at a grand solution to the fair allocation of emission rights, but recasting the problem in ways which minimize the redistributive aspects of the negotiations.

\section{* THE COSTS OF ADJUSTMENT $\mathscr{k}$}

Fair burden sharing requires some notion of the costs of mitigation-the societal costs of lowering emissions. While there have been extensive calculations on the costs to different societies, there is a simple approach that suggests why those costs will be limited. By most accounts, the adjustments to a low carbon economy could be achieved through the imposition of a moderate carbon tax (or an equivalent cap and trade system). Such a carbon charge, say at the rate of $\$ 80$ to $\$ 100$ a ton, would, of course, raise substantial revenue and allow a reduction in other taxes. The standard approach for estimating the societal cost of such a carbon charge is the dead weight loss associated with the charge, the sum of the consumer and producer surpluses associated with raising the price of carbon from its current level to $\$ 80$ or 100 a ton. (These calculations do not include the societal benefit of the reductions in climate change, just the direct economic cost of the "tax" itself.) These numbers are referred to as Harberger triangles, and are typically relatively small (though perhaps they might not be when emission reductions exceed 80\%). But the reduction of the other taxes (say on labor or capital) would have a corresponding benefit, an increase in consumer and producer surplus. Thus the net societal cost of reducing emissions is the difference between the Harberger triangles; the difference is a number that is likely to be small for most countries, and in many cases will even be positive; and the difference in the differences can be even smaller.

Thus, it is plausible that most would see their own private gains from the reductions in climate change more than offsetting the costs (possibly negative) that they would bear. Though some might see themselves gaining more than others, most would see the agreement as positive. 
But within many countries, there would be large losers: in the oil producing countries, for instance, oil producers and owners of oil assets would be worse off. While in principle, again, the winners could more than compensate the losers, such compensation is seldom made. Thus, the fact that the country as a whole might be better off does not necessarily mean that the country's government would actually support the agreement: the losers (the oil industry) may have disproportionate voice in many countries. (That is evidently the case, for instance, in the United States.)

Still, the approach we have outlined has even a political economy advantage: an argument that the country as a whole would be better off, even if particular special interests would be worse off, should carry weight. Arguments from the oil industry against an agreement would be seen for what they are: self-serving.

But there is an approach that would provide even more impetus to a global agreement. If those countries without a large fossil fuel lobby could agree to a common level of a carbon price, none would be viewed as having an unfair advantage over the other. In effect, a country which does not charge the full social cost of carbon is subsidizing carbon emitting industries, an unfair trade/competitive advantage, not unlike that of a country which subsidizes labor. These countries could impose trade sanctions - a cross border tax-on those who do not implement the common carbon price (Stiglitz 2006a, Helm 2010). (As I explain in Stiglitz (2006b), such a cross border adjustment would likely be WTO legal.) This would be an effective mechanism for ensuring compliance with a global agreement—and would provide a strong argument for those not adopting a carbon tax or an equivalent mechanism to do so. For any country not doing so would in effect be granting the tax revenue associated with its carbon emission to its trading partners.

\section{* PARTIAL VS. GENERAL EQUILIBRIUM $\not ॅ$}

At a deeper level, there would be significant distributive consequences—but consequences which would arise no matter what approach was taken to reducing carbon emissions. For the intent of any global agreement is to reduce the demand for fossil fuels, and that necessarily must reduce the rents associated with fossil fuels; the recipients of those rents- the owners of the fossil fuels-will be worse off. And that will be the case even taking into account any benefits they directly receive from the reduction in the threat of climate change. That is why one should not expect a fully voluntary global agreement among all countries; in the absence of any sense of a global social responsibility framework, any country which is exporting a significant amount of fossil fuels would likely be worse off (Cramton and Stoft 2012). And even countries which import only a limited amount might not sign on, simply because of the political influence of the fossil industries.

That is why the target should be more limited: an agreement among a "coalition of willing," countries without a large domestic fossil fuel sector, with cross-border adjustments on all other countries. I suspect the combination of social consciousness and self-interest on the part of the citizens of other countries would expand the membership in this coalition, until most, if not all, countries, joined the coalition.

\section{* VOLUNTARY VS. ENFORCEABLE AGREEMENTS}

The current approach seeks voluntary reductions. Each country would "offer" up actions it would take to reduce carbon emissions. There have been significant reductions on this basis, 
and if all countries fulfill their intentions, the results would be impressive; but they would still fall far short of what is needed. Indeed, it would be remarkable if they did not. In no other area has voluntary action succeeded as a solution to the problem of undersupply of a public good. And this is especially so when there are global public goods, the benefits of which are shared by everyone in the world. There is simply insufficient "solidarity" at the global level. Social pressure works to some extent — but only to a limited extent. And that is especially true when there are large groups within our societies for whom the direct cost of taking action (the loss in value of the fossil fuel assets they own) exceeds any direct gain from reduced global warming. It is not a surprise that such groups try to convince others that there is no real danger of climate change.

That is why the soft approach advocated in recent years by the US, amongst others, based on voluntary contributions simply will not work. Agreements have to be enforceable. In the absence of a global government able and willing to impose direct fines, the most effective enforcement mechanism are trade sanctions, including the cross-border adjustments described in previous paragraphs.

\section{* FLEXIBILITY IN MAKING COMMITMENTS ״}

But countries should be given flexibility in the manner in which they meet their obligationswhether through a carbon tax or through a system of cap and trade (Cooper 2008), which could be complemented with regulatory mechanisms when their results are sufficiently measurable. Systems of auctioned emission rights are equivalent to a carbon tax. In practice, over time there will have to be adjustments in the "caps" and in the price of carbon. The notion that there is less risk to the global environment with a cap and trade is based on the presumption that we have good knowledge of the level of emissions necessary to achieve any objective in terms of changes in temperature.

Some countries seem to believe that the political economy problems posed by climate change can best be solved by compensations provided through the grants of emission rights. Others worry that such systems are themselves subject to unwanted political pressures-and corruption.

Auctioned emission rights or a carbon tax can have large distributive consequences within a country, which is why regulatory mechanisms may have some advantages: restrictions on housing, urban design, transportation, and electricity generation can achieve a substantial fraction of what is needed; the requisite changes in carbon prices, with the associated distributive consequences, may be quite large to elicit corresponding changes. It is worth noting that much of the efforts of the international community have been directed at creating such regulatory standards, e.g. in terms of fuel efficiency in cars. But such an approach opens up difficult questions: should an industry that does not pay a carbon charge be viewed as subsidized if it faces a regulatory constraint that forces it to achieve the same level of carbon emissions? It is as if the industry has faced a carbon charge, but with the proceeds reimbursed to those in the industry as a lump sum payment. Clearly, the lump sum payment is a subsidyeven though it is not a carbon subsidy. Firms in countries facing a carbon charge will rightly argue that this is unfair competition. Moreover, there are difficult issues in transparency and comparability: if there were an agreement about a global carbon price of say $\$ 80$ a ton, and some country were to combine tight regulations with a $\$ 70$ a ton general price, how would we assess whether it was complying with the regulation? It might argue that it should be given 
the flexibility of imposing, in effect, a higher carbon price in some industry (for some technologies) and a lower carbon price for others. Put aside for the moment charges of unfair competition to which such differential pricing might give rise (which arguably would be of limited relevance if the goods in question were non-traded goods). In principle, if we had enough information about the demand and supply curves, we could calculate the reduction in emissions and compare that reduction to what would have happened had there been a uniform $\$ 80$ a ton carbon price.

\section{* COMMON AND DIFFERENTIATED RESPONSIBILITIES}

The approach delineated above does not, however, adequately differentiate among the circumstances of different countries. Such differentiation was central to earlier approaches to climate change.

It is inefficient, and likely to be viewed as inequitable for producers in developing countries to face a different carbon price from those confronting firms in developed countries, giving rise to charges of unfair competition. At the same time, those from poor countries struggling to develop rightfully feel that any extra costs are taking away funds that could otherwise be used for advancing developmental objectives.

This leads to two suggestions: (a) a global green fund, financed by allocating $20 \%$ of the funds from the carbon tax (or the equivalent) imposed in developed countries. Since the magnitude of these revenues would be proportional to emissions of those countries, it would arguably be an appropriate basis for raising funds for a global green fund. And this would be particularly so since current emission levels would be highly correlated with past emissions. (This is not the only basis on which one might raise money for a global green fund. One might, alternatively, impose a charge based on consumption, on the carbon associated with the goods that individuals in different countries consume. In a competitive equilibrium, of course, charges on production and on consumption are equivalent. In practice, they may not be. There may, however, be more technical difficulties in levying a charge on consumption than production.)

The revenues from a global green fund would be used to help finance expenditures in developing countries on adaptation and on the incremental costs associated with mitigation measures reducing carbon emissions. The funds could also be used to help developing countries pursue objectives of carbon sequestration-paying them to maintain forests (which would have additional global benefits in terms of biodiversity) and even not to extract hydrocarbons. The contribution to each of the developing countries from the Green Fund should be large enough to compensate them for accepting the global carbon price. (It may, however, be problematic to ask each country what contribution from the Green Fund would induce them to participate; that would give rise to a bargaining problem where some developing countries might claim that they need large compensation. Equity may require establishing a rule based allocation mechanism.)

(b) Improvements in technology are likely to play an important role in meeting the goals of reductions in carbon emissions. Developing countries rightly worry that, should they sign on to an enforceable agreement concerning reductions in carbon emissions, to meet agreed upon reductions would necessitate their paying developed countries large amounts to use their technology. In effect, a global carbon agreement would be an arrangement to transfer large 
amounts from developing countries to the developed. Developing countries understandably are reluctant to sign on to an international conventional that would have that as a result.

In the 1992 Rio agreement, there was a provision for compulsory licenses. And yet, the United States (and other developed countries) continue a stance which entails, in effect, a renegotiation of this provision.

The developed countries are in a better position to finance and conduct research leading to technologies which reduce carbon emissions and which lead to carbon storage at affordable costs. They should provide this technology freely to developing countries (perhaps on a sliding scale, with reduced charges for middle income countries). Some of the costs might be met out of the global green fund: research expenditures to reduce carbon emissions are a double global public good - research itself is a global public good; and climate change is itself a global public good.

\section{* CONCLUDING COMMENTS $\stackrel{k}{*}$}

It is now more than two decades since the world recognized the threat of climate change. And yet there has been little progress - too little progress-beyond a global agreement that we should take actions to limit the increase in temperature to 2 degrees $\mathrm{C}$. We are now set on a course in which we will almost surely miss even this modest goal.

We have explained why the approaches of the past - voluntary caps and actions-will almost surely fail, falling far short of what is needed. We have outlined another approach, based on a global agreement around a common carbon price, with flexibility on how each country implements that agreed upon price. With strong border adjustments, this is more likely to result in an agreement. Perhaps the agreement will initially be only among a large number of countries, a coalition of the willing, in which some recalcitrant countries refuse to join in-most likely those in which fossil fuel industries play an important role in the political economy. But we have explained how over time, even many of these will find it desirable to join the coalition. We have explained too how we can incorporate within this approach the recognized principal of "common but differentiated" responsibility.

It is time to give this alternative approach a chance. Climate change is too important to allow the current impasse to continue.

\section{References}

Cooper, R. (2008). “The Case for Charges on Greenhouse Gas Emissions," Harvard Project on International Climate Agreements Discussion Paper 08-10.

Cramton, P. and S. Stoft (2012). "Global Climate Games: How Pricing and a Green Fund Foster Cooperation," Economics of Energy \& Environmental Policy, 1:2. http://dx.doi.org/10.5547/2160-5890.1.2.9.

Helm, D. (2010). “A carbon border tax can curb climate change," Financial Times, September 5.

Stiglitz, J.E. (1995) "The Theory of International Public Goods and the Architecture of International Organizations," Background Paper No. 7, Third Meeting, High Level Group on Development Strategy and Management of the Market Economy, UNU/WIDER, Helsinki, Finland, July 8-10, 1995.

Stiglitz, J.E. (2006a). “A New Agenda for Global Warming," The Economists'Voice, 3:7. http://dx.doi.org/10.2202/ 1553-3832.1210.

Stiglitz, J.E. (2006b). “Saving the Planet,” Making Globalization Work, chapter 6.

Stiglitz, J.E. (2006c). "Global Public Goods and Global Finance: Does Global Governance Ensure that the Global Public Interest is Served?” in Advancing Public Goods, Jean-Philippe Touffut, ed., Edward Elgar Publishing, Great Britain, pp. 149-164. 
Stiglitz, J.E. (2011). "Sharing the Burden of Saving the Planet: Global Social Justice for Sustainable Development," in Mary Kaldor and Joseph E. Stiglitz, eds., The Quest for Security: Protection without Protectionism and the Challenge of Global Governance, New York: Columbia University Press, pp. 161-190. (Originally presented as Keynote speech at the meeting of the International Economic Association, Istanbul, June 2008.)

WRI and UNDP (2015). "Designing and preparing Intended Nationally Determined Contributions (INDCs)," World Resource Institute and United Nations Development Program. 